\title{
BMJ Open Understanding the patient experience of early unplanned hospital readmission following acute care discharge: a qualitative descriptive study
}

\author{
Julie Considine (D) , ${ }^{1,2}$ Debra Berry (D) , 2,3 Stephanie K Sprogis (D) , ${ }^{3}$ \\ Evan Newnham, ${ }^{4,5}$ Karen Fox, ${ }^{4}$ Peteris Darzins, ${ }^{4,5}$ Helen Rawson (D) , 1,6 \\ Maryann Street (iD ${ }^{1,2}$
}

To cite: Considine J, Berry D, Sprogis SK, et al. Understanding the patient experience of early unplanned hospital readmission following acute care discharge: a qualitative descriptive study. BMJ Open 2020;10:e034728. doi:10.1136/ bmjopen-2019-034728

- Prepublication history and additional material for this paper are available online. To view these files, please visit the journal online (http://dx.doi. org/10.1136/bmjopen-2019034728).

Received 10 0ctober 2019 Revised 29 February 2020 Accepted 22 April 2020

Check for updates

(C) Author(s) (or their employer(s)) 2020. Re-use permitted under CC BY-NC. No commercial re-use. See rights and permissions. Published by BMJ.

For numbered affiliations see end of article.

Correspondence to Professor Julie Considine; julie.considine@deakin.edu.au

\section{ABSTRACT}

Objectives To understand from a patient and carer perspective: (1) what features of the discharge process could be improved to avoid early unplanned hospital readmission (within 72 hours of acute care discharge) and (2) what elements of discharge planning could have enhanced the discharge experience.

Design A qualitative descriptive design was used. Study data were collected using semi-structured interviews that were transcribed verbatim and analysed using inductive thematic analysis. Data related to participant characteristic were collected by medical record audit and summarised using descriptive statistics.

Setting Three acute care hospitals from one health service in Australia.

Participants Patients who had an early unplanned hospital readmission and/or their carers, if present during the interviews and willing to participate, with patient permission. Findings Thirty interviews were conducted ( 23 patients only; 6 patient and carer dyads; 1 carer only). Five themes were constructed: 'experiences of care', 'hearing and being heard', 'what's wrong with me', 'not just about me' and 'all about going home'. There was considerable variability in patients' and carers' experiences of hospital care, discharge processes and early unplanned hospital readmission. Features of the discharge process that could be improved to potentially avoid early unplanned hospital readmission were better communication, optimal clinical care including ensuring readiness for discharge and shared decisionmaking regarding discharge timing and goals on returning home. The discharge experience could have been enhanced by improved communication between patients (and carers) and the healthcare team, not rushing the discharge process and a more coordinated approach to patient transport home from hospital.

Conclusions The study findings highlight the complexities of the discharge process and the importance of effective communication, shared decision-making and carer engagement in optimising hospital discharge and reducing early unplanned hospital readmissions.

\section{INTRODUCTION}

In Australia, the demand for hospital care is increasing, while average hospital length
Strengths and limitations of this study

- This study is one of the first studies to describe patients' experience of early unplanned hospital readmission.

- The use of semi-structured interviews provided an opportunity to elicit detailed information about patients' and carers' experiences of an early unplanned hospital readmission.

- Although study participants varied in age, the majority were born in Australia and as English proficiency was a requirement of participation, the study findings may not reflect the perspectives of patients and carers from culturally and linguistically diverse backgrounds.

- As data could not be collected from patients who declined participation, it is possible that the study findings are not transferable to other patients and that participants and non-participants differ in important characteristics and experiences.

of stay (LOS) is decreasing. ${ }^{1}$ Unplanned hospital readmissions within 28 days of hospital discharge are a key indicator of quality and safety of healthcare. ${ }^{2-4}$ For patients and families, unplanned hospital readmissions are potentially distressing, inconvenient and increase the risk of healthcare-related harm. Australian studies report unplanned readmission rates within 28 days of $7.4 \%-10.9 \%^{56}$ and the median time to unplanned hospital readmission as 9 days $^{7}$ to 10 days. $^{58}$

In Australia, risk factors for unplanned readmission within 28 days are age $\geq 65$ years; ${ }^{7}$ comorbidities or chronic disease ${ }^{57}$ discharge following an emergency admission $;{ }^{7}$ discharge against medical advice; ${ }^{5}$ complications during the index admission; ${ }^{7}$ index admission stay more than 2 days $^{7}$ and health service use in the preceding 6 months. ${ }^{7}$ Further, the majority $(90.6 \%)$ of unplanned readmissions 
occur via the emergency department $(\mathrm{ED}) .^{7} \mathrm{~A}$ recent systematic review of 60 international studies detailing 73 predictive models for readmission within 28 and 30 days of discharge reported that the predictive models were inconsistent in their performance and had only moderate discrimination. ${ }^{4}$

Previous work from the study setting showed that the highest risk period for an unplanned hospital readmission is within the first 3 days of hospital discharge. ${ }^{7}$ Of patients who experience a hospital readmission within 28 days of discharge, $24.4 \%$ of patients return within 3 days; however, little is known about this patient cohort. ${ }^{7}$ For $8 \%-10 \%$ of patients who have an unplanned hospital readmission, the readmission occurs on the first day of discharge. ${ }^{5}$ One in eight unplanned readmissions within 1 day were deemed preventable and one quarter of patients experiencing unplanned readmission within 1 day were discharged on a Friday or weekend. ${ }^{9}$ Pain was the most common reason for readmission within 1 day. ${ }^{9}$ Index discharge from a short stay unit was associated with the highest proportion of preventable unplanned readmissions within 1 day. ${ }^{9}$ The published literature to date has focused on identifying patient characteristics and other risk factors for unplanned hospital readmissions. ${ }^{40-15}$ The patient experience of unplanned hospital readmission is poorly understood and qualitative studies to date have focused on clinician perspectives ${ }^{1617}$ or specific patient groups such as older patients, ${ }^{18}$ patients with heart failure ${ }^{19}$ or survivors of critical illness. ${ }^{20} \mathrm{~A}$ recent study where 36 medical patients who experienced unplanned hospital readmission within 30 days were interviewed showed that many patients attributed their readmission to underlying illness. ${ }^{21}$ Although $63 \%$ did not identify factors they thought could have prevented hospital readmission, communication deficits between health professionals, and between health professionals and patients, was a dominant theme. ${ }^{21}$ Despite having important perspectives to offer, the patient and carer view of early unplanned hospital readmissions is underreported in the literature.

\section{Aims}

The aims of this study were to understand, from patient and carer perspectives: (1) what features of the discharge process could be improved to avoid early unplanned hospital readmission and (2) what elements of discharge planning could have enhanced the discharge experience. In this study, a carer was defined as a family member or other person who is significant to the patient, and an early unplanned hospital readmission was defined as occurring within 72 hours of acute care discharge. The focus of this study was patients who experienced an early unplanned hospital readmission based on the premise that an unplanned readmission so soon after acute care discharge would be a tumultuous and distressing event for patients and carers, and easily remembered by patients and carers.

\section{METHODS}

\section{Study design}

A qualitative descriptive design was used ${ }^{22}$ adopting methods from Patton. ${ }^{23}$ A qualitative descriptive design was appropriate for this study because the intent was to understand the experience of early unplanned hospital readmissions directly from those experiencing this event, ${ }^{22}$ and using the meanings patients and carers attributed to early unplanned hospital readmissions to address the research questions. ${ }^{24}$ The framework for data collection involved semi-structured interviews ${ }^{23}$ as this allowed elicitation of information using questions related to the study aims and also enabled patients and carers to elaborate on their experiences of early unplanned hospital readmissions. ${ }^{25}$ This study was conducted according to the National Health and Medical Research Council national statement on ethical conduct in research involving humans ${ }^{26}$ and Declaration of Helsinki. ${ }^{27}$

\section{Setting}

The study was undertaken in three acute care hospitals within one major Australian health service that has approximately 100000 acute care admissions annually. ${ }^{28}$ The hospitals were a 600-bed tertiary referral centre, and 250 bed and 155 bed metropolitan hospitals. Patient characteristics and admission data were collected from the electronic medical record. Data related to patients' experiences of early unplanned hospital readmission were collected using semi-structured interviews. The consolidated criteria for reporting qualitative research guidelines were used to guide the study conduct and reporting. ${ }^{29}$

\section{Patient and public involvement}

This research was conducted without patient involvement. Patients were not invited to comment on the study design and were not consulted to develop patient relevant outcomes or interpret the study findings. Patients were not invited to contribute to the writing or editing of this document for readability or accuracy.

\section{Participants}

The study participants were consecutive patients who experienced an early unplanned hospital readmission. A daily report generated by the health service was used to screen potential participants against the inclusion and exclusion criteria (table 1). Patients who met the inclusion criteria were approached by their primary nurse who read a scripted explanation of the project and sought permission for the researchers to visit. Carers were also invited to participate if they were present and the patients agreed to their participation. The researcher explained the project to patients (and carers) in plain language, provided a written plain language statement, and completed a formal written consent process for both the interview and medical record access.

Of the 110 patients who experienced early unplanned readmission, 69 patients were excluded: 35 patients had 
Table 1 Inclusion and exclusion criteria

\begin{tabular}{ll}
\hline Inclusion criteria & Exclusion criteria \\
\hline Early unplanned hospital & Clinically too unwell to \\
readmission ( $\leq 72$ hours of & participate. \\
acute care discharge). & Unable to consent to \\
participate (non-English \\
Aged $\geq 18$ years. & speaking or cognitive \\
Readmitted to acute & \\
medical, acute surgical or & impairment). \\
short stay unit. & \\
Clinically stable. & \\
Able to consent to & \\
participate (English & \\
speaking, cognitively & \\
intact). & \\
\hline
\end{tabular}

been discharged before the research team were able to commence the recruitment process; 12 patients had cognitive impairment or language barriers; 11 patients were too clinically unwell; 9 patients had a planned readmission and for 2 patients, there was no primary nurse available to approach the patient. A total of 41 patients were approached to participate in the study; 30 agreed to participate and 11 declined. There were 19 patients from the tertiary hospital, 7 patients from the mid-size metropolitan hospital and 4 patients from the smaller metropolitan hospital.

\section{Data collection}

The interviews were conducted by two female research fellows (DB and SS) between 4 December 2018 and 1 February 2019: both were registered nurses who had no prior contact with, or nursing care responsibilities for, the study participants. The interviews were conducted at the patients' bedside using an interview guide (online supplementary appendix 1), were audiorecorded, and were a maximum of $21 \mathrm{~min}$ duration (average $=10.6 \mathrm{~min}$ ). The interview guide was informed by the literature ${ }^{30-32}$ and previous work related to unplanned hospital readmissions within 1 day of acute care discharge that highlighted that discharge planning is poorly understood, ${ }^{9}$ and particularly the patient perspective of discharge planning. Interview numbers were deemed sufficient when data saturation had been reached. Data saturation was determined then the research fellows conducting the interviews perceived that the content of the interviews was becoming repetitive and that no new information was emerging. The interview transcripts were also checked to confirm that no new content was emerging. Patient characteristics, and the characteristics and outcomes of the index admission and readmission, were collected by medical record audit.

\section{Data analysis}

Data were analysed following thematic analysis framework recommended by Braun and Clarke. ${ }^{33}$ This approach to analysis was appropriate as it enabled construction of themes from the data in relation to specific research

\begin{tabular}{|c|c|c|}
\hline Data & Code & Theme \\
\hline $\begin{array}{l}\text { 'One minute you're lying in the bed } \\
\text { and another minute someone comes } \\
\text { up and says ...the doctor's okayed } \\
\text { you to go. I'll get your paperwork'. }\end{array}$ & $\begin{array}{l}\text { 'You're right } \\
\text { to go'- } \\
\text { clinician- } \\
\text { initiated } \\
\text { discharge }\end{array}$ & $\begin{array}{l}\text { All about } \\
\text { going } \\
\text { home }\end{array}$ \\
\hline $\begin{array}{l}\text { 'I thought I was over my pain and so } \\
\text { I thought well, I'm taking up a bed } \\
\text { here so I'm right to go home. But } \\
\text { then I got home and pretty quickly } \\
\text { realised I'd made a bad mistake'. }\end{array}$ & $\begin{array}{l}\text { 'Patient } \\
\text { keen to } \\
\text { go'- } \\
\text { patient } \\
\text { desire to be } \\
\text { home }\end{array}$ & \\
\hline $\begin{array}{l}\text { 'I was discharged Tuesday } \\
\text { morning...I was asked the } \\
\text { questions, are you okay? any } \\
\text { pain?... we all like to be in our own } \\
\text { beds, and we all think that being } \\
\text { at home is the best medicine. You } \\
\text { don't get any rest in hospital'. }\end{array}$ & $\begin{array}{l}\text { 'Patient } \\
\text { keen to } \\
\text { go'- } \\
\text { patient } \\
\text { desire to be } \\
\text { home }\end{array}$ & \\
\hline
\end{tabular}

questions. $^{33}$ The interviews were transcribed verbatim using a professional transcribing service and the transcripts were verified by members of the research team. The transcripts were not returned to participants. Thematic analysis, with an inductive approach, was undertaken by three researchers (JC, DB, MS) using Braun and Clarke's six-step framework ${ }^{33}$ : (1) become familiar with the data; (2) generate initial codes; (3) search for themes; (4) review themes; (5) define and name themes and (6) write-up the final report. The three researchers independently read the transcripts to familiarise themselves with the data. Data were coded separately and then the researchers came together to refine the codes and construct and review themes through a consensus process. All authors then reviewed the transcripts and confirmed themes. An open coding process was used, so codes were not set, but developed and modified during the coding process. ${ }^{33}$ Example interview data and their respective codes and themes are shown in table 2. Data related to participant characteristics and characteristics of the index admission and discharge and readmission and discharge were summarised using descriptive statistics.

\section{FINDINGS}

\section{Participant characteristics}

Thirty-six people participated in 30 interviews (patient only $n=23$; patient and carer dyads $n=6$; carer only $n=1$ ). Five carers were the patients' partners or spouses and one carer was a patient's daughter. Most patients $(n=22$, $73.3 \%)$ were born in Australia; $53.3 \%(n=16)$ were male and their median age was 57 years $(\mathrm{IQR}=40.8-76.0)$. The patient characteristics are displayed in table 3 .

\section{Index admission and readmission characteristics}

The characteristics of the index admission and discharge, and readmission and discharge are detailed in online 


\begin{tabular}{|c|c|c|}
\hline & $\mathbf{n}$ & $\%$ \\
\hline \multicolumn{3}{|l|}{ Gender* } \\
\hline Male & 16 & 53.3 \\
\hline Female & 14 & 46.7 \\
\hline \multicolumn{3}{|l|}{ Age (years) } \\
\hline $18-44$ & 9 & 30.0 \\
\hline $45-64$ & 9 & 30.0 \\
\hline$\geq 65$ & 12 & 40.0 \\
\hline \multicolumn{3}{|l|}{ Country of birth } \\
\hline Australia & 22 & 73.3 \\
\hline India & 1 & 3.3 \\
\hline Italy & 1 & 3.3 \\
\hline Netherlands & 1 & 3.3 \\
\hline New Zealand & 1 & 3.3 \\
\hline South Africa & 2 & 6.6 \\
\hline United Kingdom & 1 & 3.3 \\
\hline Not stated & 1 & 3.3 \\
\hline \multicolumn{3}{|l|}{ Usual place of residence } \\
\hline Private residence, lives alone & 8 & 26.7 \\
\hline Private residence, lives with others & 20 & 66.7 \\
\hline $\begin{array}{l}\text { Residential aged care facility (nursing } \\
\text { home) }\end{array}$ & 2 & 6.7 \\
\hline
\end{tabular}

${ }^{*}$ All patients identified as male or female.

supplementary table 1 . Most $(\mathrm{n}=23,76.7 \%)$ index admissions were via the ED and the median ED LOS was 3.25 hours ( $\mathrm{IQR}=2.82-6.05)$. General surgery and emergency medicine were the most common admitting units for index admissions. For one-third of patients $(n=10$, $33.3 \%$ ), the index discharge occurred on a weekend and the median hospital LOS was 1.73 days ( $\mathrm{IQR}=0.42-3.91)$. For the majority of patients $(n=24,80 \%)$, the index discharge involved new medications: $60.0 \%$ of patients $(n=18)$ were discharged with analgesics and $33.3 \%(n=10)$ were discharged with antibiotics.

Most patients ( $\mathrm{n}=27,90 \%)$ were readmitted with a diagnosis directly related to their index admission diagnosis. All readmissions occurred via the ED, and the median ED LOS was 4.72 hours $(\mathrm{IQR}=3.36-6.11)(\mathrm{p}=0.523)$ which was comparable to the index ED LOS. General medicine and general surgery were the most common admitting units for readmissions. The median hospital LOS following readmission was 4.06 days $(\mathrm{IQR}=2.60-6.70)$ which was significantly longer than the index admission hospital LOS of 1.73 days $(\mathrm{p}=0.002)$.

\section{Themes constructed}

Five themes relating to the patient/carer experience of readmission were constructed from interview data: 'Experiences of care'; 'Hearing and being heard'; 'What's wrong with me?'; 'Not just about me' and 'All about going

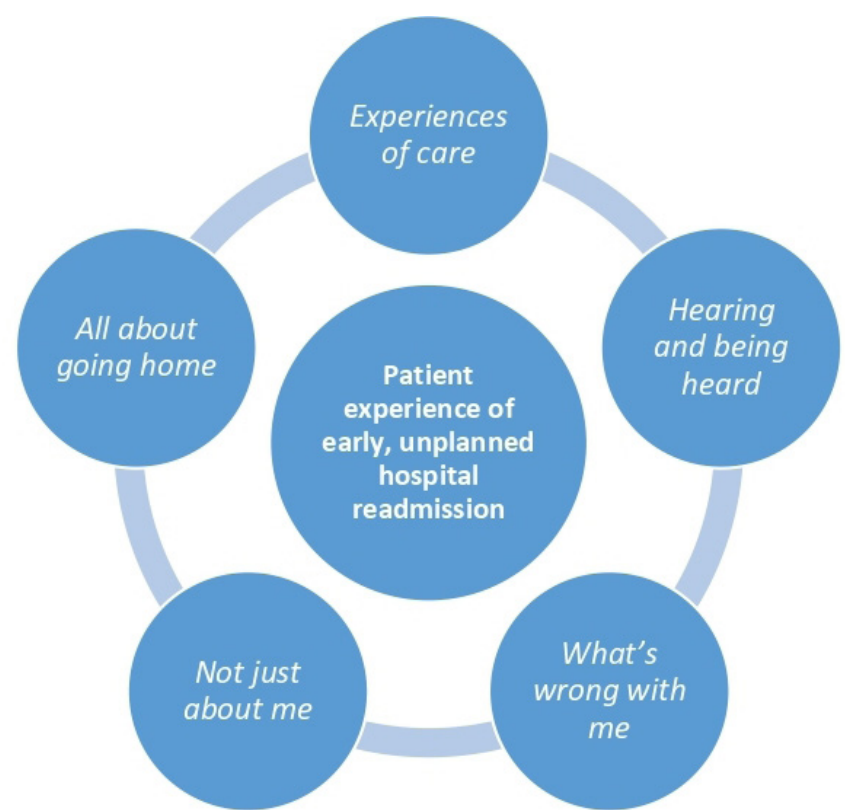

Figure 1 Themes related to patient experience of early, unplanned hospital readmission.

home' (figure 1). Figure 1 illustrates the themes as they relate to the patients' experiences of care and illustrates the features of the discharge process could be improved to avoid subsequent hospital readmission; and highlights the elements of discharge planning that could have enhanced the discharge experience.

Theme 1: experiences of care

This theme relates to the patient experience of care and while primarily focused on the index admission, also includes care during the discharge process and in some cases, the readmission. Positive experiences of care were related to perceived supportive interactions with staff who were described as 'amazing', 'wonderful' and 'attentive':

...I had an amazing nurse...really wonderful. She kept coming and checking on me...when I was in a lot of pain because she couldn't give me pain killers, ... she just stopped and chatted. It's almost like my second experience was so good that it's cancelled out the first one. (Case 4: female, mid-30s)

...They were very, very attentive. All the staff...They made us aware of the fact that until we hear from the doctor to say that yes, you can go home. As soon as they heard that very quickly thereafter we got the document to get home. No, they were very, very good. (Case 6: male, late-70s)

There were negative experiences related to clinical care which participants believed contributed to their discharge and subsequent readmission. Participants described suboptimal clinical aspects of care which they had no control over, such as lack of pain relief, diagnostic errors and the need to 'start from the beginning' when readmissions needed to occur via the ED. These experiences 
were 'awful' and resulted in participants feeling 'angry', 'furious' and 'frustrated'.

...I was sent [home] with no pain killers or any referrals, despite being in pain. I was told to go back to my GP [general practitioner] the next morning...I was a bit frustrated because I felt like I was going home in no better state than when I arrived. (Case 4: female, mid-30s)

I was angry then...why didn't they do that [ultrasound] Friday. That would have been so easy to eliminate it [bowel obstruction]. Either way they said-oh, the drip therapy, nasogastric, sent me up to the ward... I thought...they're treating it conservatively... Then I had to sign off consent that it could have been a resection, a straightforward one, or I might have a temporary colostomy... I was furious then. Because it'll massively affect my work and my entire life. (Case 19: female, mid-50s)

Yes, 12 hours down there [in the emergency department]...it's awful, because you've got to go through the system again...if they discharge you and you're not well when you get home, surely, they could take you back...my daughter rang the hospital and they said no, once you've been discharged, can't do anything. (Case 27: female, early-80s)

\section{Theme 2: hearing and being heard}

'Hearing and being heard' relates to communication and information exchange. Some patients felt they did not get the information they needed because staff were too busy or the information was not delivered in an understandable way that then impacted on how they managed once they went home. One participant described 'doctor language', which might work between doctors but not between doctors and patients.

Doctors, when they're talking to each other, they talk in doctor language. But they also bloody well do it when they're talking to the patients and you haven't got a clue. (Case 26: male, mid-90s)

The lack of engagement from staff and no discussion about discharge planning, especially for an elderly relative, was a shared concern for patients and carers and resulted in a suboptimal discharge experience.

...we didn't ask enough questions. (Case 1: male, mid-90s)

...they didn't ask enough questions I think. It's not up to us to ask questions. It's for them to find out what situation you're going to... That's the problem. Nobody asked. We just got a phone call to say come and pick him up. There was no discussion with the family... It was just a phone call. I've been coming in twice a day...somebody could have talked to me. (Daughter of case 1: male, mid-90s)

Another patient felt that having an avenue to communicate after discharge with the healthcare professionals who were involved in her care would have been useful in enabling her to manage at home and potentially avert the need for hospital readmission.

...you might be able to give me a little bit of advice over the phone, or something like that. But there's a central number which gets you to the hospital, and to outpatients, or whatever, but there's no form of contact. I know the medical staff...they're all really busy... and there are hundreds and thousands of patients...but it just would be nice if there was some point of contact that felt a little bit more familiar. (Case 23: female, early-50s)

Other patients described interactions with healthcare professionals during the discharge process but felt they were not heard or that the interaction was to serve clinicians' interests rather than patients' interests.

Because I feel like the instructions are given almost to avoid liability...I don't know if they are or not, but I feel like...sometimes things are said colloquially... like if you feel worse, yeah, yeah. (Case 19: female, mid-50s)

One patient noticed communication deficits between members of the healthcare team that was more obvious during their hospital readmission:

One of the things that I've found even being back in the second time the communication is not the greatest...everybody is fantastic but they don't talk to one another. The surgeon will come in or a doctor will come in or a resident and he'll talk to me and say you've got A, B, C but then they walk out and they don't tell the nurses, so the nurses will come and say what did they say? (Case 9: male, early-60s)

Conversely, a few patients felt they did receive adequate information about their care and the communication between clinicians was effective.

Yeah, I got all the information on what to do, all the exercises that I needed to do, all places that were going to contact me, rehab places and so forth, which they did. (Case 25: male, mid-50s)

\section{Theme 3: what's wrong with me?}

This theme relates to the diagnostic uncertainty experienced by patients which at times left them without answers, 'clueless' and 'wondering', particularly when they were discharged from hospital without a clear diagnosis:

I had a bit of a quandary with the doctors because one doctor said I had gallstones. One doctor said I had kidney stones. One doctor said I had a hernia. Then the fourth doctor said I had infected appendix...I didn't know what was wrong with me...because I've got four different people tell me four different things and now they reckon it's none of those things. (Case 14: male, late-50s) 
'Tests' are often perceived to provide the answers but for a few patients, tests were a source of waiting and sometimes, did not provide the answers they were looking for. There was also a patient perception that tests were performed to prove what was already known before sending the patient home.

When you start asking they say, well, we'll wait until we've got the tests back. So it's like a batsman just batting up and patting the ball away all the time... it seems like...we know what's wrong and you know what's wrong but we've got to prove it and as yet we haven't done that. (Case 18: male, mid-70s)

\section{Theme 4: not just about me}

'Not just about me' relates to the impact of a failed discharge and readmission on carers. For many participants their families and carers were their support networks:

I'd gone through the night of throwing up and making a mess, and I went, something's just not right here. Then sent my husband off to work. He said, what do you want me to do? I said, you go to work because I knew my mum was coming. Then we decided then that we'd come back in. It was just the easiest thing to do. (Case 23: female, early-50s)

Other participants expressed concern that their discharge from hospital was a source of stress for carers.

My husband now needs to put me to bed and that put him through a lot of stress... he was now used to also being on his own and here I come and bring all of these problems to him. (Case 3: female, early-80s)

...I had to get the neighbour to help me because I hurt myself picking her up. I can hardly walk because of her. (Husband of case 3: female, early-80s)

Some carers also voiced concerns about whether or not their relative was ready to leave hospital making the discharge experience less than desirable and, in some cases, pre-empting an unplanned return to hospital.

....at about six o'clock he [my husband] called to say they said he could come back, so I went to collect him and he seemed to be quite chirpy but also struggled to stand up...I was walking back through emergency I almost stopped and said, I don't think I should be taking this man home. But you doubt yourself, you think, oh, they know what they're doing. (Wife of case 12: male, early-70s)

I mean he's already better than he was....but he's still not going home. I asked for a discharge plan before we knew he was already in the transit lounge...I said, what is his discharge plan...he said, he hasn't got one. Anyway, it's not going to happen again I can tell you... We're a lot more proactive this time. (Daughter of case 1: male, mid-90s)
Theme 5: all about going home

'All about going home' relates to discharge decisions and includes clinician-initiated discharge, patients for whom discharge was their preferred option and patients who left against clinical advice. Participants described clinician-initiated discharge as a negative experience of 'being kicked out' and feeling 'rushed off' and 'pressured':

...one min you're lying in the bed and another minute someone comes up and says you're okay to gothe doctor's okayed you to go. I'll get your paperwork. Five minutes later I feel like I'm kicked out. (Case 14: male, late-50s)

I felt a bit down. I got home and I said, I think-we both said we think we've been sent home too early. We believed we'd been sent home too early. I was having a little bit of trouble breathing .... (Case 17: male, early-70s)

In hindsight, I probably should have stayed here for another couple of days. That's only my thoughts on it. Remember, there was a long holiday weekend and the joint [ward] was flat-out. (Case 26: male, mid-90s)

A few patients were keen to go home and for one patient, being at home was more therapeutic than being in hospital.

I was discharged Tuesday morning...I was asked the questions, are you okay? any pain?...we all like to be in our own beds, and we all think that being at home is the best medicine. You don't get any rest in hospital... (Case 23: female, early-50s)

Another patient described feeling ready to go home but then once at home, realising he needed more support than he had anticipated, so returned to hospital.

I thought I was over my pain and so I thought well, I'm taking up a bed here so I'm right to go home. But then I got home and pretty quickly realised I'd made a bad mistake...so my wife brought me back two hours later...I said I'd go because I thought I was feeling better. So at the end of the day it was my fault, no one else's. (Case 5: male, mid-50s)

Other patients made the decision to leave against health professional advice. For one patient, selfdischarge was the culmination of a negative healthcare experience:

...I actually asked them if I could leave and I signed a discharge thing myself...I wasn't happy with the way I was being treated by the nurses...the doctor actually said there's nothing else I can do for you, we're just giving you medications. I said well, if that's the case, can I go home? He said yep, you just have to sign this waiver. He gave me a script for my pain relief and my medical certificate. I wasn't told anything about my wounds or the surgery that I had or anything. (Case 28: female, early-20s) 
and for another patient, a regrettable decision:

The doctor advised me to stay another night. I said no... So, I had to come back...

[when asked if there was anything the participant would have done differently] ...I would have listened to the doctor, so that I didn't have to come back and wait in emergency again. (Case 29: female, early-50s)

Transport home was raised as an issue by a number of participants as a negative component of the discharge process, especially the cost of taxis and how hospital systems and processes such as the use of transit lounge, did not always meet patient needs.

...sometimes they don't give you a taxi voucher, but if you can't walk the distance...then I'm puffed... all of my pension goes on taxis...because I've got no transport and I can't do it on the bus. (Case 21: male, early-60s)

...they just get you discharged, they get your bum into a wheelchair and they wheel you down and sit you at the front door and you ring your taxi...that's the way you get discharged... I won't go through the transit lounge...it's too bloody far to walk. It's better to be discharged through the front door...if you're going home by cab because they'll push you to the front door and the cab will drive up to the front door.

(Case 22: male, late-60s)

\section{DISCUSSION}

\section{Findings}

There was considerable variability in patients' and carers' experiences of hospital care, discharge processes and early unplanned hospital readmissions. The features of the discharge process that could be improved to avoid subsequent hospital readmission were better communication (between members of the healthcare team; and between the healthcare team and patients and carers), optimal clinical care and ensuring readiness for discharge and shared decision-making regarding discharge timing and goals on returning home. The elements of discharge planning that could have enhanced the discharge experience were improved communication between patients (and carers) and the healthcare team, the discharge process not being rushed and a more coordinated approach to patient transport home from hospital.

\section{Strengths and limitations}

The strengths of this study were the multidisciplinary nature of the research team and their research experience related to unplanned hospital readmissions, ${ }^{79}$ and the richness of the information provided by participants. The analysis process was robust: three researchers from nursing backgrounds coded separately and then jointly, to ensure consensus and ensure all relevant data were captured, which contributes to the credibility of the study. ${ }^{33}$ The main limitation of this work was that participants were self-selecting which raises two possible issues. First, although our study participants varied in age, the majority were born in Australia and English proficiency was a requirement of participation. The findings, therefore, may not reflect the perspectives of patients from culturally and linguistically diverse backgrounds. Second, the characteristics and experiences of non-participants may be quite different to those of participants so the findings only reflect the experiences of patients included in this work, and non-participants may have a very different perspective.

A carer was interviewed along with the patient on six occasions and there was one instance where the patient was unable to participate so the carer was interviewed in isolation. There is debate about the ethics of interviewing carers and patients together, ${ }^{34}$ however, in instances where the carer was present, their participation was at the patient's request. Permission to proceed with the interviews with the carer present was confirmed with the patient prior to commencing the interview. Further, it was thought important to capture the carer perspective. It is possible that carers' views do not represent patients' views or that patients or carers moderated their responses, to present socially acceptable answers. Finally, there was no patient or public involvement in this study and future studies could possibly be improved by adding patients or members of the public to the research team. Carers were invited to participate in this study if they were present and were not purposefully targeted, thus, there were only seven carers involved in this study, and six of them were interviewed with the patient. Future studies should be designed to better represent the view of carers. Interviewing carers separately to patients is worthy of consideration.

\section{Comparison with existing literature}

The patients in this study were of variable age and twothirds of patients lived with others. One-third of patients were discharged on a weekend when access to services in the community is limited. There is conflicting evidence regarding the relationship between weekend discharge and unplanned hospital readmission with some studies showing no association between weekend discharge and unplanned hospital readmission within 28 days ${ }^{57}$ and others showing it was a predictor factor in unplanned hospital readmission within 1 day of discharge. ${ }^{9}$ The index admission median LOS in our study was 1.73 days which is much shorter than the national average public hospital LOS of 5.4 days. ${ }^{1}$ Other studies from the same setting have shown that patients who experienced an unplanned hospital readmission within 28 days had a longer median index admission LOS (2 days vs 1 day, $\mathrm{p}<0.001)^{7}$ and patients who had an unplanned readmission within 1 day of discharge had a median hospital LOS of 1 day. ${ }^{9}$ It is possible that patients going home after a short (1-2 days) LOS may need a different approach to discharge planning than patients whose hospital LOS is longer.

Patients in this study remarked on the communication and interactions between members of the healthcare team, and in particular, when there were gaps in communication 
between team members. The communication gaps highlighted by patients and carers in this study were contributing factor to their unplanned readmission but also contributed to a negative experience of the discharge process. Communication failures are a leading cause of harm in healthcare $^{35}$ and have been associated with a number of adverse patient outcomes including premature hospital discharge ${ }^{36}$ and unplanned hospital readmissions. ${ }^{37}$ Poor communication between clinicians was a factor in more than half of preventable adverse events occurring soon after hospital discharge. ${ }^{38}$ Communication failures can occur between clinicians or between clinicians and patients and families. Patient perceptions of good communication with medical and nursing staff, and discharge instructions are significant predictors of lower 30-day readmissions, even when controlled for other hospital-level and contextual factors. ${ }^{39}$

There were a number of influences on discharge decisions that may influence the likelihood of an unplanned hospital readmission: clinicians' assumptions that patients are ready to go home; patients' desire to go home with clinician approval and patients' desire to go home irrespective of clinicians' opinions. There are few studies of patient perceptions of their readiness to go home ${ }^{40}{ }^{41}$ despite greater readiness for discharge being predictive of fewer hospital readmissions. ${ }^{40}$ Weiss et al report that living alone, discharge education and care coordination explained $51 \%$ of readiness for discharge score variance and that patient age and discharge readiness explained $16 \%$ of variance in coping postdischarge. ${ }^{40}$ There was also disparity in nurse and patient perceptions of readiness to go home ( $\mathrm{r}=0.15-$ 0.32 ) with nurses rating patients more ready to go home than the patients' self-rating. ${ }^{42}$ Formal assessment of patient readiness for discharge as part of the discharge process may be one strategy to decrease the risk of premature discharge and subsequent hospital readmission.

Two-thirds of patients in this study lived with others, highlighting the importance of carers in the discharge process for a large number of patients. Lack of carer engagement in the discharge planning and process was noted by many patients and carers, and increased the risk of hospital readmission and contributed to a negative discharge experience. When patients and carers are engaged in their care and share in key decisions, patient safety and health outcomes are enhanced. ${ }^{43}$ However, rigid and structured hospital routines and processes unnecessarily limit interaction, engagement and negotiation between members of the healthcare team and patients and carers about discharge decisions. $^{32}{ }^{44}$ Discharge planning conversations and decisions may or may not involve patients. If patients are involved, they may have limited capacity to process information and make sound decisions by virtue of being unwell and vulnerable. Others have also noted patients were seldom involved in discharge planning, with conversations and decisions occurring at the level of healthcare team and the patient informed of the decision. ${ }^{30}$ Often carers, who will play a key role in ensuring a safe discharge process and ongoing patient support at home, are not included in these conversations or decisions, ${ }^{3132}$ or as our study showed, they are included by chance as they 'happened to be there' or if they demanded involvement.

\section{Implications for practice and policy}

The focus of this study was the patient experience of an early unplanned hospital readmission soon after hospital discharge. One in five patients have an adverse event during their transition from hospital to home: of these, $6 \%$ of events were preventable, $11 \%$ resulted in an ED attendance and $24 \%$ resulted in hospital readmission. ${ }^{38}$ Patient safety is a major focus in acute hospital care and as such, patients' clinical status and responses to therapies are frequently assessed, and prevention of complications is a major focus of care. ${ }^{45}$ However, once patients are discharged, this level of surveillance and support decreases dramatically or ceases completely. ${ }^{46}$ There have been a number of systematic reviews of the effectiveness of interventions aimed at reducing hospital readmissions when patients are discharged to home. ${ }^{10} 1346$ Interventions that commence during hospital admission and continued after discharge were more effective in reducing readmissions compared with interventions starting after hospital discharge. ${ }^{10}$ The most effective interventions to reduce hospital readmissions were those oriented towards patient engagement ${ }^{46}$ and empowerment, ${ }^{1013}$ and those that promoted patients' and carers' capacity for patient self-care. ${ }^{13}$ However, for the benefits of these interventions to be realised, financial resources and collaboration between hospitals and community and primary care providers are required..$^{13}$

\section{Implications for future research}

The discharge process is complex and multi-faceted. Predictive models for readmission within 28 and 30 days of discharge are inconsistent in their performance with only moderate discrimination ${ }^{4}$ so persisting with predictive studies may not prove useful in terms of patient outcomes. Systematic reviews have shown that hospital readmissions decreased when patient engagement, ${ }^{46}$ empowerment ${ }^{1013}$ and self-care ${ }^{13}$ were promoted. Future research could focus on the implementation and operationalisation of interventions with known effectiveness. The patient and carer experience of unplanned hospital readmissions is underreported in the literature and studies, such as this one, have focused on English-speaking patients and carers who are cognitively intact. Future work should focus on representing vulnerable populations such as those from culturally and linguistically diverse backgrounds or those who are going home with some degree of cognitive impairment.

\section{Author affiliations}

${ }^{1}$ School of Nursing and Midwifery, Centre for Quality and Patient Safety Research, Institute for Health Transformation, Deakin University, Geelong, Victoria, Australia ${ }^{2}$ Centre for Quality and Patient Safety—Eastern Health Partnership, Box Hill, Victoria, Australia

${ }^{3}$ School of Nursing and Midwifery, Institute for Health Transformation, Deakin University, Geelong, Victoria, Australia

${ }^{4}$ Eastern Health, Box Hill, Victoria, Australia

${ }^{5}$ Eastern Health Clinical School, Monash University, Box Hill, Victoria, Australia

${ }^{6}$ Centre for Quality and Patient Safety—Monash Health Partnership, Clayton, Victoria, Australia 
Twitter Julie Considine @julie_considine and Maryann Street @maryann_street

Acknowledgements The authors wish to thank Eastern Health Decision Support for their assistance with identifying readmitted patients for this study.

Contributors JC, MS, KF, PD and EN designed the study. DB and SKS collected data. DB, MS and JC analysed the study data with assistance from HR. All authors reviewed and approved themes. All authors reviewed and approved the manuscript.

Funding The authors have not declared a specific grant for this research from any funding agency in the public, commercial or not-for-profit sectors.

Competing interests None declared.

Patient and public involvement Patients and/or the public were not involved in the design, or conduct, or reporting, or dissemination plans of this research.

Patient consent for publication Obtained.

Ethics approval Ethics approval was granted by the Eastern Health Human Research Ethics Committee (LR75-2018)

Provenance and peer review Not commissioned; externally peer reviewed.

Data availability statement № data are available. Participants did not provide consent for the transcripts to be released outside Eastern Health.

Open access This is an open access article distributed in accordance with the Creative Commons Attribution Non Commercial (CC BY-NC 4.0) license, which permits others to distribute, remix, adapt, build upon this work non-commercially, and license their derivative works on different terms, provided the original work is properly cited, appropriate credit is given, any changes made indicated, and the use is non-commercial. See: http://creativecommons.org/licenses/by-nc/4.0/.

\section{ORCID iDs}

Julie Considine http://orcid.org/0000-0003-3801-2456

Debra Berry http://orcid.org/0000-0002-8780-054X

Stephanie K Sprogis http://orcid.org/0000-0003-4259-6976

Helen Rawson http://orcid.org/0000-0001-5363-729X

Maryann Street http://orcid.org/0000-0002-5615-141X

\section{REFERENCES}

1 Australian Institute of Health and Welfare. Admitted patient care 2017-18: Australian hospital statistics. health services series No. 90. cat. No. HSE 225. Canberra: Australian Institute of Health and Welfare, 2019from. https://www.aihw.gov.au/reports/hospitals/ admitted-patient-care-2017-18/contents/at-a-glance

2 Health Innovation and Reform Council. Presenting the data considered in preparation of advice regarding improvement to unplanned readmission performance in Victoria. Melbourne, Victoria: Victorian Government, Department of Health, 2013.

3 Gruneir A, Dhalla IA, van Walraven C, et al. Unplanned readmissions after hospital discharge among patients identified as being at high risk for readmission using a validated predictive algorithm. Open Med 2011;5:104-11.

4 Zhou H, Della PR, Roberts P, et al. Utility of models to predict 28-day or 30-day unplanned Hospital readmissions: an updated systematic review. BMJ Open 2016;6:e011060.

5 Li JYZ, Yong TY, Hakendorf P, et al. Identifying risk factors and patterns for unplanned readmission to a general medical service. Aust Health Rev 2015;39:56-62.

6 Bucknall T, Digby R, Fossum M, et al. Exploring patient preferences for involvement in medication management in hospitals. J Adv Nurs 2019;75:2189-99.

7 Considine J, Fox K, Plunkett D, et al. Factors associated with unplanned readmissions in a major Australian health service. Aust Health Rev 2019;43:1-9.

8 McLean R, Mendis K, Canalese J. A ten-year retrospective study of unplanned Hospital readmissions to a regional Australian hospital. Aust Health Rev 2008;32:537-47.

9 Considine J, Berry D, Newnham E, et al. Factors associated with unplanned readmissions within 1 day of acute care discharge: a retrospective cohort study. BMC Health Serv Res 2018;18:713.

10 Braet A, Weltens C, Sermeus W. Effectiveness of discharge interventions from hospital to home on hospital readmissions: a systematic review. JBI Database System Rev Implement Rep 2016;14:106-73.

11 García-Pérez L, Linertová R, Lorenzo-Riera A, et al. Risk factors for hospital readmissions in elderly patients: a systematic review. QJM 2011;104:639-51.
12 Kansagara D, Englander H, Salanitro A, et al. Risk prediction models for hospital readmission: a systematic review. JAMA 2011;306:1688-98.

13 Leppin AL, Gionfriddo MR, Kessler M, et al. Preventing 30-day Hospital readmissions: a systematic review and meta-analysis of randomized trials. JAMA Intern Med 2014;174:1095-107.

14 van Walraven $C$, Bennett $C$, Jennings $A$, et al. Proportion of hospital readmissions deemed avoidable: a systematic review. CMAJ 2011;183:101860:E391-402.

15 Vest JR, Gamm LD, Oxford BA, et al. Determinants of preventable readmissions in the United States: a systematic review. Implement Sci 2010;5:88.

16 Clark B, Baron K, Tynan-McKiernan K, et al. Perspectives of clinicians at skilled nursing facilities on 30-day Hospital readmissions: a qualitative study. J Hosp Med 2017;12:632-8.

17 Okoniewska B, Santana MJ, Groshaus H, et al. Barriers to discharge in an acute care medical teaching unit: a qualitative analysis of health providers' perceptions. J Multidiscip Healthc 2015;8:83.

18 Dilworth S, Higgins I, Parker V. Feeling let down: an exploratory study of the experiences of older people who were readmitted to hospital following a recent discharge. Contemp Nurse 2012;42:280-8.

19 Simmonds R, Glogowska M, McLachlan S, et al. Unplanned admissions and the organisational management of heart failure: a multicentre ethnographic, qualitative study. BMJ Open 2015;5:e007522

20 Donaghy E, Salisbury L, Lone NI, et al. Unplanned early Hospital readmission among critical care survivors: a mixed methods study of patients and carers. BMJ Qual Saf 2018;27:915-27.

21 LeClair AM, Sweeney M, Yoon GH, et al. Patients' perspectives on reasons for unplanned readmissions. J Healthc Qual 2019;41:237-42.

22 Bradshaw C, Atkinson S, Doody O. Employing a qualitative description approach in health care research. Glob Qual Nurs Res 2017;4:233339361774228.

23 Patton MQ. Qualitative research and evaluation methods: integrating theory and practice: thousand oaks. CA: Sage, 2015.

24 Neergaard MA, Olesen F, Andersen RS, et al. Qualitative description - the poor cousin of health research? BMC Med Res Methodol 2009;9:52.

25 Liamputtong P. Research methods in health foundations for evidence-based practice. 3rd edn. Melbourne: Oxford Press, 2017.

26 National Health and Medical Research Council. National statement on ethical conduct in research involving humans 2007 (updated 2018. Canberra: AusInfo, 2018. https://www.nhmrc.gov.au/about-us/ publications/national-statement-ethical-conduct-human-research07-updated-18

27 World Medical Association. World Medical association Declaration of Helsinki: ethical principles for medical research involving human subjects. JAMA 2013;310:2191-4.

28 Eastern Health. Annual report 2017-2018. box Hill: eastern health, 2018. Available: https://www.easternhealth.org.au/about-us/ publications/item/833-annual-report-17-18 [Accessed 8 Sep 2019].

29 Tong A, Sainsbury P, Craig J. Consolidated criteria for reporting qualitative research (COREQ): a 32-item checklist for interviews and focus groups. Int J Qual Health Care 2007;19:349-57.

30 Ekdahl AW, Linderholm M, Hellström I, et al. 'Are decisions about discharge of elderly hospital patients mainly about freeing blocked beds?' a qualitative observational study. BMJ Open 2012;2:e002027.

31 Popejoy L. Participation of elder persons, families, and health care teams in hospital discharge destination decisions. Appl Nurs Res 2011;24:256-62.

32 Huber DL, McClelland E. Patient preferences and discharge planning transitions. J Prof Nurs 2003;19:204-10.

33 Braun V, Clarke V. Using thematic analysis in psychology. Qual Res Psychol 2006;3:77-101.

34 Norlyk A, Haahr A, Hall E. Interviewing with or without the partner present?--an underexposed dilemma between ethics and methodology in nursing research. J Adv Nurs 2016;72:936-45.

35 Dayton E, Henriksen K. Communication failure: basic components, contributing factors, and the call for structure. Jt Comm J Qual Patient Saf 2007;33:34-47.

36 Roy CL, Poon EG, Karson AS, et al. Patient safety concerns arising from test results that return after hospital discharge. Ann Intern Med 2005;143:121-8.

37 Pesko MF, Gerber LM, Peng TR, et al. Home health care: NursePhysician communication, patient severity, and hospital readmission. Health Serv Res 2018:53:1008-24.

38 Forster AJ, Murff HJ, Peterson JF, et al. The incidence and severity of adverse events affecting patients after discharge from the hospital. Ann Intern Med 2003;138:161-7. 
39 Mitchell JP. Association of provider communication and discharge instructions on lower readmissions. J Healthc Qual 2015;37:33-40.

40 Weiss ME, Piacentine LB, Lokken L, et al. Perceived readiness for hospital discharge in adult medical-surgical patients. Clin Nurse Spec 2007;21:31-42.

41 Bobay KL, Jerofke TA, Weiss ME, et al. Age-Related differences in perception of quality of discharge teaching and readiness for hospital discharge. Geriatr Nurs 2010;31:178-87.

42 Weiss M, Yakusheva O, Bobay K. Nurse and patient perceptions of discharge readiness in relation to postdischarge utilization. Med Care 2010;48:482-6.

43 Ringdal M, Chaboyer W, Ulin K, et al. Patient preferences for participation in patient care and safety activities in hospitals. BMC Nurs 2017;16:69.
44 Huby G, Brook JH, Thompson A, et al. Capturing the concealed: interprofessional practice and older patients' participation in decision-making about discharge after acute hospitalization. $J$ Interprof Care 2007;21:55-67.

45 Australian Commission on Safety and Quality in Health Care (ACSQHC). National safety and quality health service standards. Second Edn. Sydney: Australian Commission on Safety and Quality in Health Care, 2017. https://www.safetyandquality.gov.au/ wp-content/uploads/2017/12/National-Safety-and-Quality-HealthService-Standards-second-edition.pdf

46 Hansen LO, Young RS, Hinami K, et al. Interventions to reduce 30-day rehospitalization: a systematic review. Ann Intern Med 2011;155:520-8. 